Editorial

\title{
Can We Consider Scholarship of Teaching Learning Rather than Focusing Only on Publications for Recognition of Medical Teachers by National Medical Commission?
}

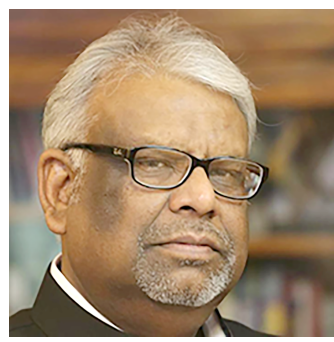

Piyush Gupta

\author{
Tejinder Singh ${ }^{1}$ Piyush Gupta ${ }^{2}$ \\ ${ }^{1}$ Department of Pediatrics and Medical Education, Sri Guru Ram Das \\ Institute of Medical Sciences and Research, Amritsar, Punjab, India \\ ${ }^{2}$ Department of Pediatrics, University College of Medical Sciences, \\ New Delhi, India
}

Ann Natl Acad Med Sci (India):2021;57:1-2

A peer-reviewed publication has become synonymous with scholarship and is generally considered an essential for academic promotions and progression. However, there are a lot of ifs and buts with this assertion. Often, publications are made for the sake of publication, with little applicability or novelty. It has been rightly said that "publications are like a pair of pants. If you have them, nobody notices but if you do not have them, then everyone starts looking at you"! Naturally, the focus of the faculty is to publish or risk perishing.

Medical teachers in India have to don multiple hats. In the traditional roles of medicine, viz. patient care services, teaching and research, their time and energy are spent in the same order of priority. In addition, many of the teachers at a higher level in the hierarchy have to perform administrative duties as well, leaving little quality time for research. Most of the research that happens in Indian medical schools, comes out of PG theses, where again the focus is on producing a document as a passport for appearing in the examinations. Much of this seems to unwittingly support the comment "The average PhD thesis is nothing but a transference of bones from one graveyard to another," attributed to Frank Dobie (Goodreads). Lack of funds, equipment, infrastructure, training, and avenues pose further problems.

To this, one can add lack of motivation to produce quality research and publications. With new and newer medical colleges coming up every year, the need for medical teachers is ever rising. In such a buyer's market, the requirement for quality research and publications is often ignored. An analysis of publication output from Indian teaching institutions

Address for correspondence Piyush Gupta, MD, FAMS, FIAP, FNNF, Department of Pediatrics, University College of Medical Sciences, New Delhi 110095, India (e-mail: prof.piyush.gupta@gmail.com).
DOI https://doi.org/ $10.1055 / \mathrm{s}-0041-1728179$ ISSN 0379-038X

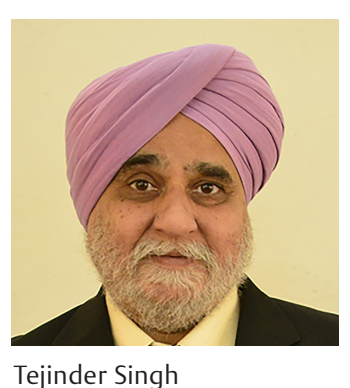

during 2005 to 2014 revealed that only $4.3 \%$ institutions produced more than 100 papers a year, which accounted for $40.3 \%$ of the country's research output. ${ }^{1}$ However, $57.3 \%$ of the medical colleges did not have any publication during this period. Interestingly, if analyzed state wise, $90 \%$ colleges of Karnataka and Kerala did not have any publication during this period. During the corresponding period, Mayo Clinic published 3,700 papers.

If we must identify one factor which is responsible for growth and expansion of modern medicine over traditional forms, it would probably be research. Quality medical research improves patient care, improves medical education, reduces budgetary expenditure, and benefits the society at large. ${ }^{2,3}$ The diverse population demography and differences in the disease pattern also warrant that we have quality research covering Indian population. ${ }^{4}$

The then regulator of medical education, Medical Council of India (MCI), duly recognized the importance of research to improve teaching and health care and has given various guidelines since 2009, and modified them in 2010, 2015, 2017, and 2019. ${ }^{5}$ While the intent was good, the guidelines prompted medical teachers to simply publish-with neither the teachers nor the institutions having any concern for the quality. Many predatory journals made their way, offering to publish for a fee. Many of them managed to get indexing as required under extant rules. We had a personal experience where a faculty member who had submitted two papers as part of promotion application, on being pointed issues regarding authorship and methodology, managed 
to produce a different modified portable document format (pdf) of the same papers within 2 days with names of the authors changed! These practices are not un-anticipated given that not enough avenues exist for publication. Let us take the example of pediatrics. There are only two indexed pediatric journals from India, publishing around 15 original research papers per month, which is markedly inadequate for the number of teachers aspiring to publish their work. Additionally, focus on original research only takes away the space for many other important articles related to guidelines, recommendations, debates, and education. In many other specialties, the specialty journal is published bi-monthly or quarterly, creating severe space crunch.

Though MCI has notified the regulations and changed them four times within a decade, these have come under criticism from various quarters. ${ }^{6,7}$ While regulations can be framed and modified, such an approach may not meet the desired objectives. Most of the appointments and promotions of medical teachers are made by the institutions themselves, many of whom enjoy the status of a deemed University. The quality of research and publications is unlikely to come under scrutiny except when there is an "inspection" and the buyer's market is likely to self-perpetuate the status quo for its own benefits.

Boyer $^{8}$ categorized scholarship into four domains-teaching, application, discovery, and integration-and noted that discovery scholarship has eclipsed the other scholarships to become the most valued. Since it is easy to document, it is taken as the first evidence of scholarship. Can we look for other ways and means to judge scholarship? There are many opportunities in the day-to-day work of medical faculty, which can provide evidence of scholarship.

Glassick et $\mathrm{al}^{9}$ built on the concept of Boyer and gave criteria for classifying certain activities as scholarly. These include-clear goals, adequate preparation, appropriate methods, significant results, effective presentation, and reflective critique. Morahan and Fleetwood ${ }^{10}$ have pointed out that the criteria for scholarship in North America and Europe has already enlarged to include educational innovations and faculty development as well. They suggested a double-helix model for academic progression, with one strand for clinical work and the other for scholarship activities. If for example, one strand is "teaching students," the other can be "to teach others how to teach and assess in offline and online settings." If one strand is "providing clinical services," then the other can be "training teachers how to design and implement programs." This approach is likely to bring scholarship into daily activities of medical teachers and improve the quality of teaching-learning, which was the first reason for focusing on scholarship.

Can we consider scholarship of teaching learning (SOTL) rather than focusing only on scholarship of discovery? SOTL is defined as systematic inquiry into student learning which advances the practice of teaching in higher education by making inquiry findings public. ${ }^{11}$ Yet another definition proposed by Darling ${ }^{12}$ is "work that encourages an empirical examination of teaching in relation to student learning.
It is distinct from scholarly teaching in that it goes beyond teaching well, even superbly, to participating in a focused inquiry process and reflective practice about one's own teaching." Felten ${ }^{13}$ further identified five principles for good practice in SOTL: (1) inquiry focused on student learning, (2) grounded in context, (3) methodologically sound, (4) conducted in partnership with students, and (5) appropriately public. It has been rightly pointed out by Morahan and Fleetwood $^{10}$ that the two helical strands of SOTL represent separate but intertwined components. Of course, it will require an appropriate set of criteria to evaluate such an approach. How such a scholarship can be evaluated? Should it focus on output or outcome?

With our long association with teacher training and faculty development, both in teaching and service areas, we often ask ourselves-are we getting any scholarship credit for this work? The answer may lie in recognizing the SOTL.

\section{Conflict of Interest}

None declared.

\section{References}

1 Ray S, Shah I, Nundy S. The research output from Indian medical institutions between 2005 and 2014. Curr Med Res Prac 2016;6:49-58

2 Asokan N, Shaji KS. Methods to enhance capacity of medical teachers for research publications. Indian J Public Health 2016;60(2):154-158

3 Aggarwal R, Gogtay N, Kumar R, Sahni P; Indian Association of Medical Journal Editors. Indian Association of Medical Journal Editors. The revised guidelines of the medical council of India for academic promotions: need for a rethink. Indian Pediatr 2016;53(1):23-26

4 Tullu MS, Karande S. Quality research in Indian medical colleges and teaching institutions: the need of the hour. J Postgrad Med 2016;62(4):213-215

5 Patra A, Chaudhary P, Ravi KS. Adverse impact of COVID-19 on anatomical sciences teachers of India and proposed ways to handle this predicament. Anat Sci Educ 2021;14(2):163-165

6 Bandewar SV, Aggarwal A, Kumar R, Aggarwal R, Sahni P, Pai SA. Medical Council of India's amended qualifications for Indian Medical Teachers: well-intended, yet half-hearted. Natl Med J India 2018;31(1):1-4

7 Bandewar SV, Pai SA. Regressive trend: MCl's approach to assessment of medical teachers' performance. Indian J Med Ethics 2015;12(4):192-195

8 Boyer EL, Scholarship Reconsidered: Priorities of the Professoriate. San Francisco: Jossey-Bass; 1997 1-26

9 Glassick CE, Huber MT, Maeroff GI, Boyer EL, Scholarship Assessed: Evaluation of the Professoriate. Special Report of Carnegie Foundation for the Advancement of Teaching. San Francisco: Jossey-Bass;1997:1-49

10 Morahan PS, Fleetwood J. The double helix of activity and scholarship: building a medical education career with limited resources. Med Educ 2008;42(1):34-44

11 Hutchings P, Shulman LS. The scholarship of teaching: new elaborations, new developments. Change 1999;31(5):11-15

12 Darling AL. Scholarship of teaching and learning in communication: new connections, new directions, new possibilities. Commun Educ 2003;52(1):47-49

13 Felten P. Principles of good practice in SoTL. Teaching and Learning Inquiry 2013;1(1):121-125 